\section{Commentary: Is there more than one way to shine a penny? International Training Variation While Standardizing Cardiothoracic Surgery Excellence}

\author{
Ann E. Hwalek, DO, and Nahush A. Mokadam, MD
}

The road to standing in an operating room as a cardiothoracic surgeon is not short, elementary, or simple. In the United States, the training pathways can range by multiple years and cover a diverse scope of learning objectives within the averaged 7 short years. This type of platform is unparalleled in our education system in the United States. As we educate elementary students to high schoolers, Common Core State Standards offer guidelines for simply what should be known. ${ }^{1}$ The training of an elite surgeon with the highest levels of education lacks this precision across the globe, yet the patient population demands the same highquality outcome for the patient and their families. Therefore, the question is this: Would a standardized global curriculum for trainees improve the standard of care for patients with cardiothoracic disease worldwide? Further, would a core set of standards provide the trainee guidance to navigate the diverse training pathways to the cardiothoracic operating room? Although our specialty is not alone in our evaluation of training, cardiothoracic surgery needs to be pushed beyond summaries and recommendations and work to implement a global curriculum. ${ }^{2,3}$ The lack of standardization of curriculum and regulation of certification is a critical issue for several reasons. Although attenuated training can result from undesired patient outcomes, prolonged training presents many obstacles to the trainee, including financial hindrances and delayed personal or family goal fulfillment. A common final examination covering

\footnotetext{
From the Division of Cardiac Surgery, The Ohio State University Wexner Medical Center, Columbus, Ohio.

Disclosures: Dr Mokadam is a consultant for Medtronic, Abbott, SynCardia, and Carmat. Dr Hwalek has nothing to disclose with regard to commercial support.

Received for publication Feb 19, 2020; accepted for publication Feb 19, 2020; available ahead of print March 10, 2020.

Address for reprints: Nahush A. Mokadam, MD, Division of Cardiac Surgery, The Ohio State University, Columbus, OH 77030 (E-mail: Nahush.Mokadam@ osumc.edu).

J Thorac Cardiovasc Surg 2021;161:175-6

$0022-5223 / \$ 36.00$

Copyright (C) 2020 by The American Association for Thoracic Surgery

https://doi.org/10.1016/j.jtcvs.2020.02.095
}

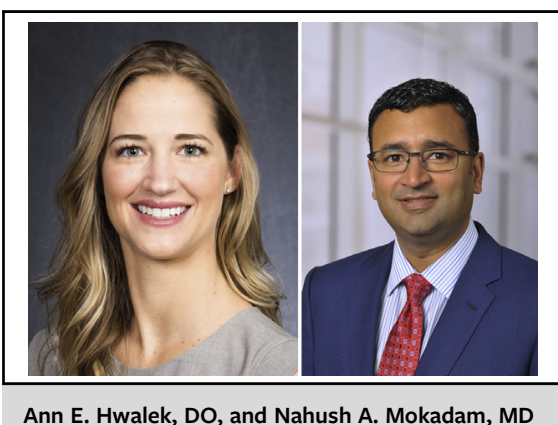

\begin{abstract}
CENTRAL MESSAGE
Globally, cardiothoracic training pathways vary greatly in length and quality of training. Educators and trainees should join together to produce definitive measures for a standardized curriculum and certification.
\end{abstract}

objectives established via a global curriculum could help determine training duration and ultimately provide recommendations toward further preparation or advancement into independent practice. Through this examination, each country or system can assess the training for strengths and weaknesses, which allows for national program building and international evaluation of cardiothoracic training. A global syllabus can also address operative experience by establishing minimal case requirements and defining specified levels of participation and autonomy within the range of cardiothoracic operations. Development of case requirements and participation guidelines would allow for a greater global discussion and perspective sharing of educational techniques and methods to progress a trainee. Further exposure to simulation in the institutional setting or at regional societal meetings would provide trainees and evaluators from different locations the exposure of training variations. Recognizing institutions with a worldwide certification would convey trainees with an accepted global designation allowing for distinction for healthcare systems and patients to recognize.

In this issue of the Journal, Nissen and colleagues ${ }^{4}$ describe multinational training arrangements and corresponding recommendations for numerous countries over multiple variants. The study allows for the reader to formulate a global perspective while cross referencing individual countries, such as the United States, and collective systems, 
such as the European Union. Additionally, this work addresses the variability among cardiothoracic, cardiac, and thoracic surgery pathways. After exhibiting a large body of tabulated comparisons, the authors formulate recommendations covering the assessed categories. Although the recommendations lack specificity for standardization, they acknowledge the unique needs of each country.

Cardiothoracic surgery has an ever-changing future as a specialty with ongoing diversifying scopes of practice because of emerging technologies and earlier specialization to address unmet needs of the ongoing disease burden. ${ }^{5}$ The variation of training will only be intensified in this trajectory. As the Accreditation Council for Graduate Medical Education in the United States works to realign milestones for thoracic residency programs and the Society for Thoracic Surgeons continues to refine the national surgical curriculum, there is precedent for such a movement and a model of the personnel needed to achieve such an important task. As the Accreditation Council for Graduate Medical Education's Thoracic Milestones outline cardiac, thoracic, and professional standard requirements, training programs could use this as a format to distinguish objections and to guide a trainee on the basis of intended practice paths of a cardiac only, thoracic only, or combined cardiothoracic career. Definitive measures for producing guidelines for standardization must be at the highest level priority to our specialty worldwide. Although standardization might be a long road in development, the trainees and, ultimately, the trainee's future patients will benefit from its completion.

\section{References}

1. National Governors Association. Common Core State Standards; 2010. Washington, DC, 2010. Available at: http://www.corestandards.org/about-the-standards/ development-process/. Accessed February 4, 2020.

2. Are C, Caniglia A, Malik M, Cummings C, Lecoq C, Berman R, et al. Variations in training of surgical oncologists: proposal for a global curriculum. Ann Surg Oncol. 2016;16:1769-81.

3. Are C, Berman RS, Wyld L, Cummings C, Lecoq C, Audisio RA. Global curriculum in surgical oncology. Ann Surg Oncol. 2016;23:1782-95.

4. Nissen AP, Smith JA, Schmitto JD, Mariani S, Almeida RMS, Afoke J, et al. Global perspectives on cardiothoracic, cardiovascular, and cardiac surgical training. J Thorac Cardiovasc Surg. 2021;161:168-74.e5.

5. Zilla P, Yacoub M, Zühlke L, Beyersdorf F, Sliwa K, Khubulava G, et al. Global unmet needs in cardiac surgery. Glob Heart. 2018;13:293-303.
See Article page 168.

\section{Commentary: Learning cardiothoracic surgery: More similar than not}

\author{
James I. Fann, MD
}

By combining previous reports of cardiothoracic surgery education and communication with educators in the many regions of the world, Nissen and colleagues ${ }^{1}$ provide the reader with the most comprehensive comparison of training programs to date. On first pass, differences appear to exceed the similarities. Of these is the variability among programs

From the Department of Cardiothoracic Surgery, Stanford University, Stanford, Calif. Disclosures: Author has nothing to disclose with regard to commercial support.

Received for publication Feb 4, 2020; accepted for publication Feb 6, 2020; available ahead of print Feb 14, 2020.

Address for reprints: James I. Fann, MD, Department of Cardiothoracic Surgery, Stanford University, 300 Pasteur Drive, Stanford, CA 94305 (E-mail: jfann@ stanford.edu).

J Thorac Cardiovasc Surg 2021;161:176-7

0022-5223/\$0.00

Published by Elsevier Inc. on behalf of The American Association for Thoracic Surgery

https://doi.org/10.1016/j.jtcvs.2020.02.006

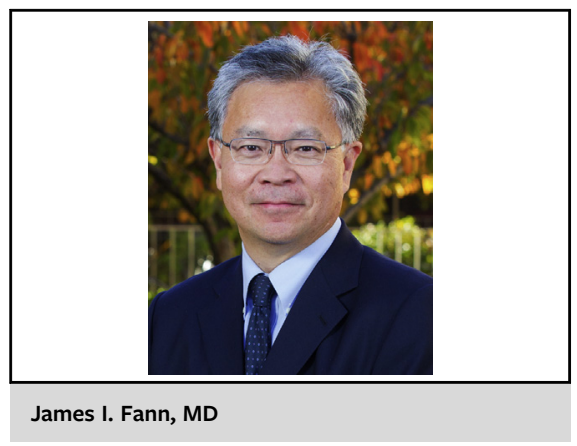

CENTRAL MESSAGE

Addressing challenges in cardio-

thoracic surgery training will

benefit from continued dialogue,

which in turn depends on better

understanding of each program.

in the assessment of trainees during and at the end of training. Worldwide and over several decades, leading surgical educators have addressed the needs and changes of the 